\title{
Studies on Chromium-free Conversion coatings on Aluminum
}

\author{
OKI, M \\ National Open University of Nigeria, School of Science and Technology \\ 14/16 Ahmadu Bello Way, Victoria Island, Lagos, Nigeria
}

\begin{abstract}
The development of a chromium-free conversion coating on aluminum has been studied using transmission electron microscopy (TEM), Auger Electron (AES) and Secondary ion mass spectroscopy (SIMS) techniques. Within the limits of the resolution of the TEM, the coating is uniformly clear and featureless. It is composed essentially of Zirconium Oxide over a diffused layer of Zirconium and Aluminum Oxides. @JASEM
\end{abstract}

Conversion coatings are formed in-situ by electrochemical reactions with the metal surface. This results in modification of the metal surface, such that the coating formed is an integral part of the parent metal. Such coatings find application as a good base for paint adhesion, where surface features, both micro and macro, may be important in the improvement of paint adhesion on aluminum (Thompson et al 2000).

Although, chromate and chromate-phosphate conversion coatings have been in use for decades and they both provide improvement in corrosion resistance and paint adhesion on aluminum. Recent developments have made it possible for the use of non-chromium conversion coatings where effluent problems and toxicity of $\mathrm{Cr}^{6+}$ species is encountered. Establishments, such as in the canning industries, prefer the use of non-chromium conversion coatings, which is free of any chromium species. In addition, such coating must be uniformly clear, colorless in appearance, and show some improvement in adhesion to subsequently applied polymer coatings. One such non-chromium formulation incorporates a zirconium salt, boric acid and a source of fluoride in the coating solution (Oki, 2006). This type of coating is a relatively recent development, and not much has been published about its morphology, composition and other characteristics. However (Smith et al 1993) have experimented on cerium as a possible substitute for chromium. Results obtained were encouraging. In view of these shortcomings, analytical and transmission electron microscopy techniques have been employed to study the non-chromium coating on aluminum.

\section{MATERIALS AND METHODS}

Materials: Aluminum specimens, 99\% purity, of dimensions $30 \times 10 \times 1 \mathrm{~mm}$ were electro polished in a perchloric acid/ ethanol mixture for 5 minutes, rinsed in distilled water before drying in a cool air stream. The electro polished specimens were subjected to varying periods of immersion at $298 \mathrm{k}$ in a conversion coating bath containing $0.5 \mathrm{~g} / 1 \mathrm{Zr}\left(\mathrm{NO}_{3}\right)_{4}, 2 \mathrm{~g} / 1 \mathrm{NaF}$, $5 \mathrm{~g} / 1 \mathrm{H}_{3} \mathrm{BO}_{3}$ about $1 \mathrm{~m} 1 \mathrm{HNO}_{3}$ for $\mathrm{pH}$ adjustment and tartaric acid.

Methods: Prior to transmission electron microscopy examination, ultramictromed sections of the aluminum substrate and the coatings were obtained with LKB III 8800 ultra microtome. The thin samples thus prepared were examined in a Philips 301 transmission electron microscope, with further analysis of the coatings in a Philips EM400T transmission electron microscope. Information regarding coating composition was obtained using a Vacuum Generator's auger electron spectroscopy, with a $3 \mathrm{KeV}$ primary electron beam and current of 200 uA. Depth profile analysis was obtained by alternate analysis and in-situ ion beam etching of the specimens. During secondary ion mass spectrometry runs, the coatings were sputtered, using gallium ions with a beam current of $4 \mathrm{nA}$. Appropriate elemental profiles were obtained by monitoring the intensities of instrumentally induced ions of aluminium, fluorine etc for a period of 30 minutes.

\section{RESULTS AND DISCUSSIONS}

Initial visual observation of specimens treated for various times in the coating bath showed that the specimens remained reflective after $15 \mathrm{mins}$ of treatment. Indicating that, any coatings formed within this period are thin and colourless. Also any irregularity and roughening at both the coating solution and metal coating interfaces were minimal.

The sectional morphology of the ultramictromed section of the specimen treated for 1 min revealed that the initial thin electro polishing film had been replaced by a coating of about $17 \mathrm{~nm}$ in thickness. The relatively thin coating has undulating metal/coating and coating solution interfaces. The 
coating apparently highlighted the metal surface topography, with distances between the ridges ranging from about $50 \mathrm{~nm}$ to $120 \mathrm{~nm}$. In addition, features were not resolvable within the film section, indicating a clear coating of uniform contrast. However, a finely textured region adjacent to the metal interface was observed. A typical micrograph of a section through the coating developed for $5 \mathrm{~min}$, attached to the metal substrate is displayed in Fig. 1.

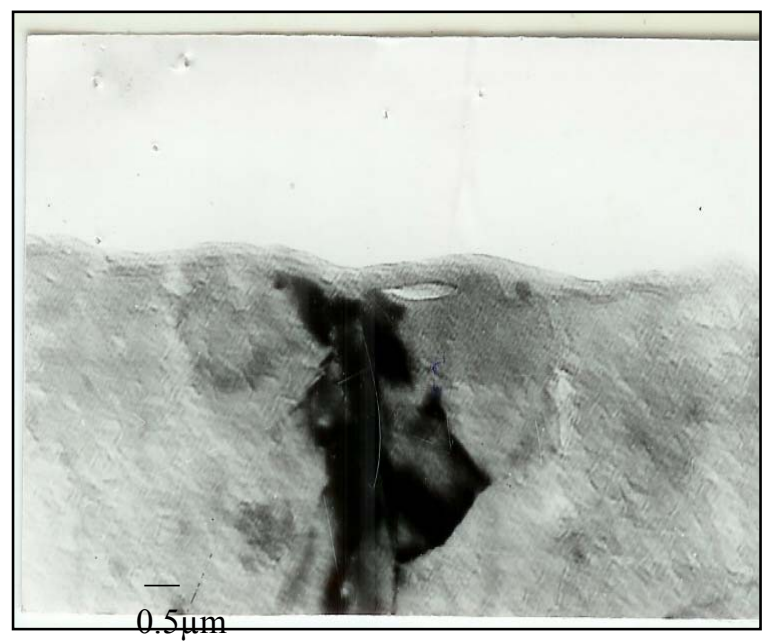

Fig.1 Transmission Electron Micrograph of the coating developed for $5 \mathrm{mins}$ in non-chromate bath.

Whereas, displayed in Fig. 2 is the transmission electron micrograph of a similar coating, stripped from its aluminum substrate using $0.5 \mathrm{M}$ mercuric chloride solution.

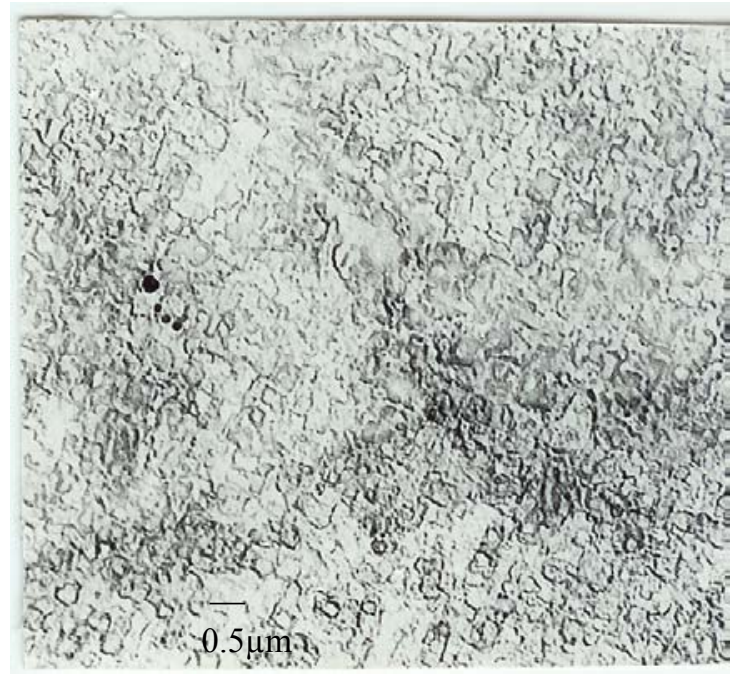

Fig.2 Transmission Electron Micrograph of Striped coating developed for 5 mins

The coating showed light and dark materials, which decorated and highlighted the grain and sub-grain boundaries of the substrate aluminum. These are portions of different thickness of the coating. No features were resolvable within the coating.

Energy depressive analysis of X-rays in the STEM using a nominal probe size of $10 \mathrm{~nm}$ at various positions in the films developed after different times of treatment indicated only aluminum. It appeared that the major component of the coating is aluminum, which is present as hydrated alumina. Any $\mathrm{Zr}$ present was not detected. The EDX has a limited elemental detection capability approximately, $0.1 \% \mathrm{wt}$.

Auger Electron Spectroscopy: A typical Auger electron spectroscopy surface scan for coating formed for 5 minutes, Fig3, displayed peaks for the presence of zirconium at $147 \mathrm{eV}$; Oxygen at $505 \mathrm{eV}$ and Fluorine at $652 \mathrm{eV}$, with a relatively low aluminum at $1387 \mathrm{ev}$. In addition, carbon, which is a surface contaminant, appeared at $269 \mathrm{eV}$.

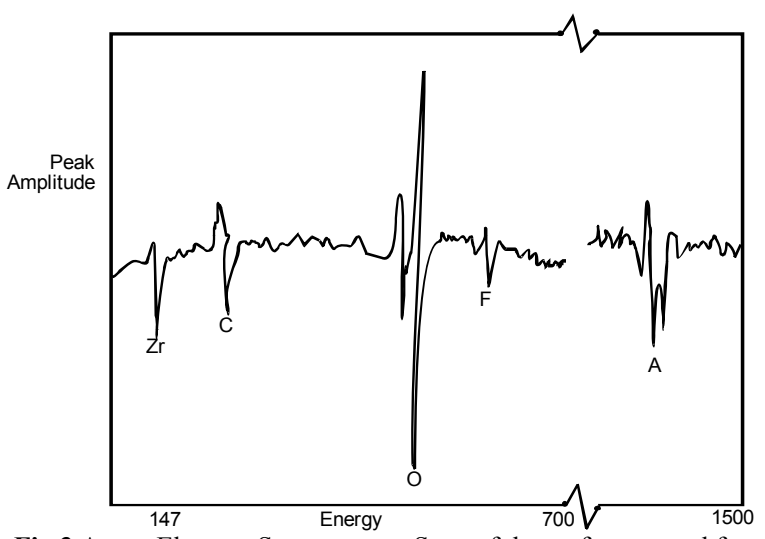

Fig.3 Auger Electron Spectroscopy Scan of the surface treated for 5 mins.

The appearance of $\mathrm{Zr}$ at $147 \mathrm{eV}$ showed the presence of $\mathrm{Zr}^{2+}$, probably as hydrated $\mathrm{ZrO}_{2}$. The sparingly soluble zirconium oxide was deposited on the macroscopic metal surface during hydrogen evolution, which occurred with the anodic dissolution of aluminum, creating $\mathrm{pH}$ increase.

The Auger electron spectroscopy profile analysis showed that the intensity of the Zirconium yield was a maximum in the film materials at the film solution interface and decreased rapidly with etching time. Thus Zirconium was present mainly in the near surface regions of the coating. Fluorine showed a peak at the outer regions of the coating where it was adsorbed as fluoride species. A further peak was observed at $60 \mathrm{~s}$ of etching after which the yield remained relatively constant. On the other hand, oxygen in the coating decreased in yield from the coating solution interface. At the outer regions, it is associated with $\mathrm{ZrO}_{2}$ and water of hydration while within the coating it will be associated with aluminum as $\mathrm{Al}_{2} \mathrm{O}_{3}$.

From the analysis, $\mathrm{Zr}, \mathrm{O}$ and $\mathrm{F}$ are the major constituents of the outer regions of the coating with 
an underlying film material, which is essentially alumina. Fluoride is generally present within the coating with relatively high intensities at the coating and metal interfaces.

Comparatively, secondary ion mass spectroscopy Figs. 4a-c confirmed the depth profile composition analysis obtained from Auger electron spectroscopy.

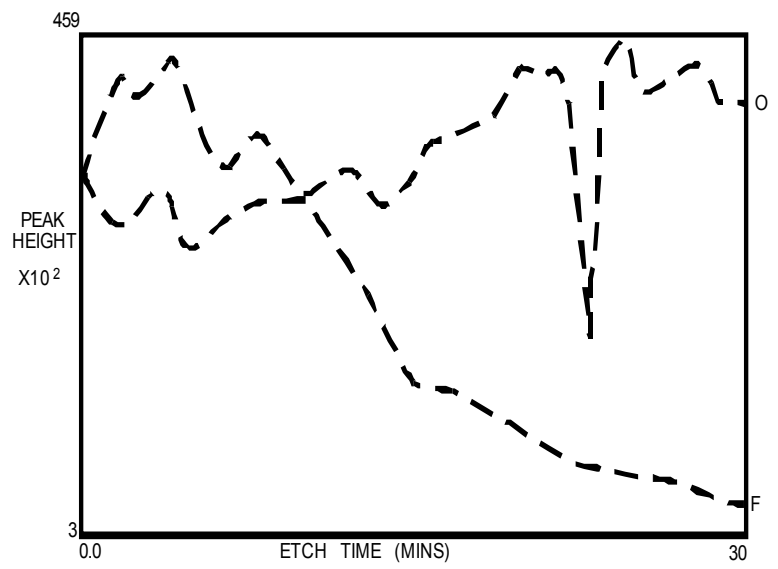

Fig 4a Secondary Ion Mass Spectrometry Analysis showing Oxygen and Fluorine Profiles.

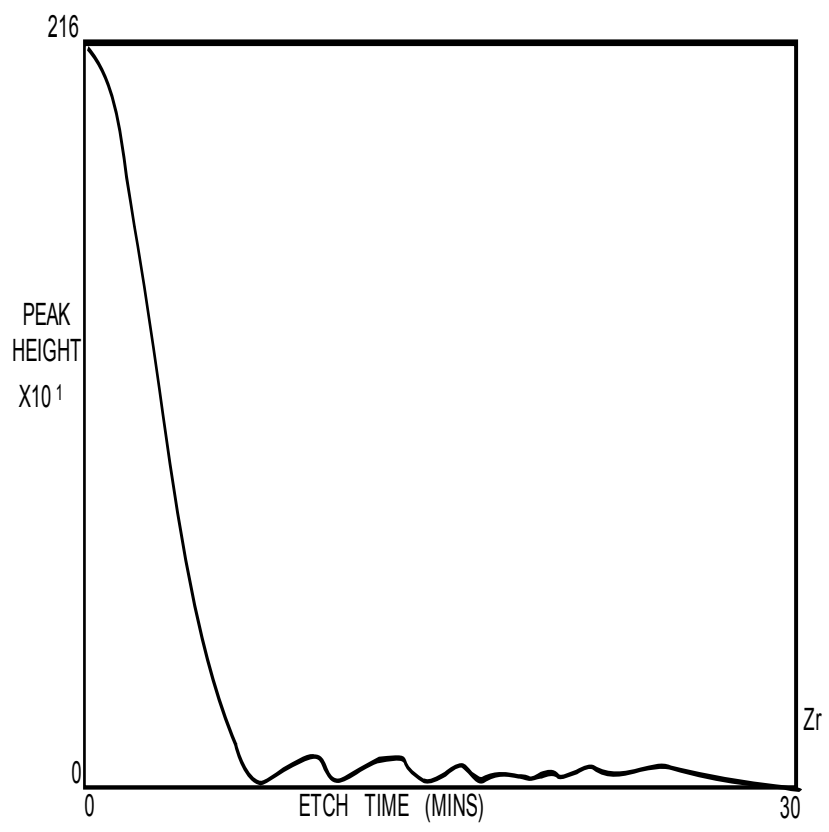

Fig.4b Secondary Ion Mass Spectrometry Analysis showing Zirconium Profile.

Significantly, Zirconium, oxygen and fluorine were present within the coating. $\mathrm{Zr}^{+}$peak, evident at the coating solution interface decayed to a relatively low level with in-situ gallium ions sputtering. Prominently $\mathrm{Al}^{+}$peak increased to a relatively steady height beyond the $\mathrm{Zr}^{+}{ }^{-}$rich surface regions of the coating.

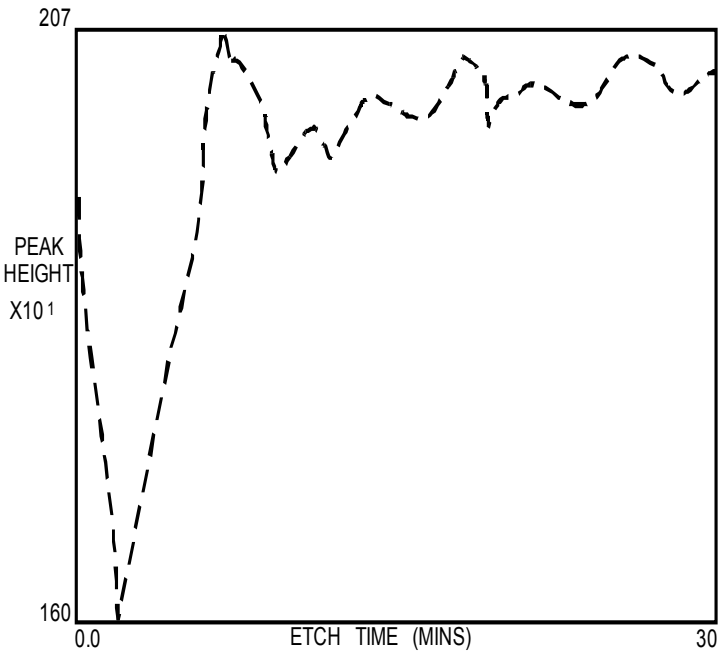

Fig.4c Secondary Ion Mass Spectrometry Analysis showing Aluminium Profile.

Eletronoptical examination revealed that the coating thickness increased slightly over the immersion period employed. This was due to the formation of hydrated Zirconium oxide, which restricts access of the coating solution species to the macroscopic metal substrate within the time limit employed $\mathrm{n}$ this investigation. However, the activation of the substrate was facilitated by the fluoride species in the coating solution by its complexing action (GonzalezNunez et al 1999). Within the $\mathrm{pH}$ range of the coating solution employed, zirconium was present as the zirconyl ion, $\mathrm{ZrO}^{2+. .}$ Additionally, in solution, $\mathrm{ZrO}^{2+}$ can develop to $\mathrm{ZrO}_{2}$ depending on the $\mathrm{pH}$ of the solution thus:

$$
\mathrm{ZrO}^{2+}+\mathrm{H}_{2} \mathrm{O} \rightarrow \mathrm{ZrO}_{2}+2 \mathrm{H}
$$

From equation (1), the removal of $\mathrm{H}+$, by cathodic reduction at the metal surface thus,

$$
2 \mathrm{H}^{+}+2 \mathrm{e}^{-} \rightarrow \mathrm{H}_{2}
$$

will enhance the deposition of $\mathrm{ZrO}_{2}$ on the macroscopic metal surface. During the anodic dissolution of aluminium, hydrogen ion reduction occurred leading to a rise in the interfacial $\mathrm{pH}$ of the solution adjacent to the metal surface. $\mathrm{ZrO}_{2}$, deposited on the metal surface is sparingly soluble in the solution from which it is precipitated.

From the analyses, $\mathrm{Zr}$, in the form of $\mathrm{ZrO}_{2}$ and absorbed $\mathrm{ZrO}^{2+}$ species in addiction to $\mathrm{F}$ were indicated in the outermost regions of the coating, with a low yield of aluminium. $\mathrm{Al}$ and $\mathrm{F}$ could have 
been occluded within the film material in the outer regions of the coating. In addition, the yield of $F$ was relatively high at the metal/coating interface, which is consistent with the idea of activating the metal substrate.

From these considerations, fluoride species in the coating solution, removed the air formed/ electopolishing film on aluminium by forming soluble complexes thus:

$$
\mathrm{Al}_{2} \mathrm{O}_{3}+6 \mathrm{HF} \quad \rightarrow 2 \mathrm{AlF}_{3}+3 \mathrm{H}_{2} \mathrm{O}
$$

Further, the fluoride complexed with aluminium generating $\mathrm{Al}$ ions in +3 oxidation state and electrons, thus:

$$
\mathrm{Al} \rightarrow\left(\mathrm{Al}^{3+} \text { F complex }\right)+3 \mathrm{e}^{-}
$$

The electrons generated were consumed by the hydrogen reduction reaction leading to increase in $\mathrm{pH}$ of the solution at the metal/ solution interface.

$$
3 \mathrm{H}^{+}+3 \mathrm{e}^{-} \quad \rightarrow \quad 3 / 2 \mathrm{H}_{2}
$$

The continual removal of $\mathrm{H}^{+}$ions from the solution at the metal surface, favoured the deposition of $\mathrm{ZrO}_{2}$, $\mathrm{nH}_{2} \mathrm{O}$ from $\mathrm{ZrO}_{2}^{+}$ion. The theory, which favoured the increase in $\mathrm{pH}$ of the solution due to hydrogen ion reduction, also indicated the deposition of hydrated alumina from $\mathrm{Al}^{3+}$ ions dissolved in the solution. Hydrated alumina was formed which accounted for the presence of an aluminium rich film material adjacent to the metal/ coating interface.

From the above considerations, the non- chromium coating is composed of two diffused layers of coating materials. The outer surface region is essentially $\mathrm{ZrO}_{2}, \mathrm{nH}_{2} \mathrm{O}$ with an inner hydrated alumina film material. The generally known rapid alumina dissolution in fluoride containing solutions supports the formation of the non- chromium coating via the deposition of $\mathrm{ZrO}_{2}, \mathrm{nH}_{2} \mathrm{O}$ from $\mathrm{ZrO}_{2}^{+}$in the coating solution.

Conclusion: Conversion coatings developed on bare aluminium in a $\mathrm{Zr}\left(\mathrm{NO}_{3}\right)_{4} / \mathrm{H}_{3} \mathrm{BO}_{3} / \mathrm{NaF}$ bath are relatively thin and the major constituents of the coating are hydrated zirconium oxide with hydrated alumina lying at the metal/coating interface.

Acknowledgement: The author acknowledges the guidance and provision of laboratory facilities by

Professor, G. E. Thompson of, School of Materials, The University of Manchester, U. K.

\section{REFERENCES}

Gonzalez-Nunez, MA; Skeldon, P; Thompson, GE; Karimzadeh, H (1999) Kinetics of development of a non- chromate conversion coating for magnesium Alloys and Magnesium- based metal matrix Composite, Corrosion 55, 1136 .

Oki, M (2006) The development of Nano - Coatings on $\mathrm{Al}-0.2 \% \mathrm{Fe}$ in Zirconium Nitrate/ Fluoride solution Journal of Nig. Env. Soc.3 (3) 293.

Smith, CJE; Baldwin, KR; Hewins, MA; Gibson, NC (1993) A study into the Corrosion inhibition of an aluminium alloy by Cerium salts" Progress in the understanding and prevention of Corrosion 1652 - 1657 Editors Costa MJ \& Mercer, AD Published by the institute of Materials, UK

Thompson, GE;Liu,Y;Skeldon,P;Smith,CJE;Shimizu, K.(2000)Chromate Conversion Coatings growth on Aluminium 2014-T6 Alloy in Proceedings of $2^{\text {nd }}$ International Symposium on Aluminium Surface Science and Technology, $21^{\text {st }}-25^{\text {th }}$ May 2000, Manchester, 479-484. 